DOI: http://dx.doi.org/10.33846/hn20707

http://heanoti.com/index.php/hn

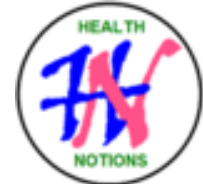

RESEARCH ARTICLE

URL of this article: http://heanoti.com/index.php/hn/article/view/hn20707

\title{
Green Tea (EGCG) Decreases Malondialdehide in Oxidative Stress Exposure to Psychological Stress
}

\author{
M. Dodi F Priaminda ${ }^{1(\mathrm{CA})}$, Bambang Wirjatmadi ${ }^{2}$, Bambang Purwanto ${ }^{3}$, Merryana Adriani $^{4}$ \\ ${ }^{1(\mathrm{CA})}$ Faculty of Public Health, Universitas Airlangga, Indonesia (Corresponding Author) \\ ${ }^{2}$ Department of Public Nutrition, Faculty of Public Health, Universitas Airlangga, Indonesia \\ ${ }^{3}$ Department of Physiology, Faculty of Medicine, Universitas Airlangga, Indonesia \\ ${ }^{4}$ Department of Public Nutrition, Faculty of Public Health, Universitas Airlangga
}

\begin{abstract}
Exposure to psychological stress can cause oxidative stress. Provision of exogenous antioxidants is expected to reduce the occurrence of oxidative stress. Green tea with its active ingredient Epigalocatechin Galat is considered to reduce the occurrence of oxidative stress. The purpose of this study was to examine the administration of green tea (EGCG) on the effect decreasing MDA levels against Wistar Strain (Rattus norvegicus) white rats exposed to psychological stress; with Randomized Post Test design of only group design by grouping into 5 groups, with control group and treatment group. Administration of steeping green tea (EGCG) with a single dose. To find out the significant influence of the independent variable on a set of variable group tested Manova. Post hoc testing using LSD (Least Significance Different) was performed to see significant differences between groups. In this study, obtained MDA data with significant decrease at the 6th hours after consum EGCG.
\end{abstract}

Keywords: oxidative stress; green tea, EGCG, malondialdehide

\section{INTRODUCTION}

Psychic stress can cause oxidative stress which can lead to various degenerative diseases ${ }^{(1)}$. Study in the United States, The National Institute for Occupational Safety and Health, states that employees who fall ill due to work stress. It can be concluded that working conditions play an important role in causing work stress ${ }^{(2)}$. Physical stress can cause oxidative stress that culminates in physical ailments that can ultimately lead to death. Deeper in other studies, psychic stress can increase free radicals that can cause oxidative stress ${ }^{(1)}$. The role of antioxidants as an antidote to early free radicals that can cause oxidative stress.

The advancement of molecular biology gives rise to the role of oxidants and antioxidants. In normal circumstances there is a balance between the two in the body. Several recent studies indicate the trigger factor of the disease is called oxidative stress, which occurs due to an increase in the number of free radicals so that the body's defense capability through the antioxidant system becomes reduced. This is influenced by reactive oxygen species (ROS). ROS is a relatively high oxidant oxidant, very unstable, so it quickly reacts with other molecules. ROS occurs both endogenously and exogenously, through regular metabolic activity, lifestyle and dietary activities ${ }^{(3)}$.

There has been much research in his efforts to inhibit free radicals. In nature there are many natural ingredients that can be consumed that are useful in inhibiting free radicals. One such natural ingredient is tea. Tea contains natural ingredients flavonoids that have antioxidant properties that can inhibit free radicals. Free radicals have been shown to cause peroxidation of lipid cell membrane, DNA damage and apoptosis ${ }^{(4)}$. Lipid peroxidation can be detected from the products it produces including $\mathrm{MDA}^{(5)}$.

Green tea as a second drink after water in teh world, is no doubt pharmacologically and epidemiologically able to prove itself as an antioxidant ${ }^{(6)}$. Green Tea has many active substances that are useful for the body and in its various functions for the health of the body. The most active substance in green tea is Epigalocatechin Galat (EGCG) ${ }^{(7)}$. 
Our study aimed to analyze and explain how EGCG in green tea can affect the levels of Malondialdehide, in which these variables have a major effect on the magnitude of free radicals in the body affected by oxidative stress due to exposure to psychological stress. This MDA compound is more commonly used as a marker of oxidative stress than other compounds in biomedical research because of its more chemically stable properties $^{(8)}$.

\section{METHODS}

This research was conducted in Biochemistry Laboratory, Faculty of Medicine, Universitas Airlangga in August to September 2017. This research was an laboratory experimental research with randomized post test only control group design. This study using animal experiments in the form of male white rats Wistar strain (Rattus norvegicus) given exposure in the form of psychological stress and then given treatment of Green Tea therapy (Camellia sinensis). The researcher used Wistar Strain and separated into 5 groups. The 2 groups were the control group and 3 other groups were the treatment group. The experimental animals used in this study were 25 male Wistar strains (Rattus norvegicus). Each group consisted of 5 white male rats. Age of mice were \pm 2-3 months with body weight 150-200 gram.

The rats were acclimitation for 7 days. Rats were divided into 5 groups. Normal Control group (K1) was not given anything, only water and standart food. Stress Control Group (K2) were given psychic stress for 1 day. The treatment group consisted of 3 groups given psychic stress for 1 day and exposure to psychic stress in rats by using a change in sleeping guard pattern, by way of daylight given the bright lights and shocks in the cage, so that sleeping mice disturbed.

The dose of green tea extract given was adjusted to the dose consumed by humans. The preparation used was a Medi Tea ${ }^{\circledR}$ green tea extract containing 125-150 MG EGCG. Determination of doses was obtained from the results of previous studies, a daily dose of $680 \mathrm{mg} /$ day catechins. Giving to humans using Laurence and Bacharach conversion tables multiplied the conversion factor of humans to rats. Dose in rats $12,24 \mathrm{mg}$ single dose or equal with 5 cup tea.

Blood samples for MDA examination, performed in accordance with the group. In the control group taking blood samples were performed after exposure to stress. In the treatment group performed on the second day after exposure to stress $1 \times 24$ hours, the second day of the treatment group given green tea. and at (P1) taken blood samples at the first hour, the group (P2) was taken at 6th, and the group (P3) was taken at 24rd hours, and blood was measured in its MDA level

MDA examination levels was performed on rat animal serum because the examination was a major marker of oxidative stress ${ }^{(3)}$. The method of examination of MDA levels was by Thiobarbituric Acid Reactive Substance (TBARSC) technique. The results was showed by spectrophotometry.

The data analysis of this study using Multivariate Analysis of Variant (Manova). Post Hoc testing using LSD (Least Significance Different) was done to see the significant differences between groups. The difference was considered significant if the p-value $<0.05$, with $95 \%$ confidence interval. Previously, the data should be fulfill One Way Anova test criteria of normal distribution with One Sample Kolmogorov-Smirnov normality test and homogenous data variations by performing the Lavene Test.

\section{RESULTS}

Based on the research, the mean of malondialdehyde (MDA) levels of all groups is presented in Table 1.

Table 1. Mean and standard deviation of MDA ( $\mathrm{nmol} / \mathrm{ml})$ of control and experimental groups on Wistar strain white rats

\begin{tabular}{ccc}
\hline Group & $\mathrm{n}$ & Malondialdehyde $(\mathrm{MDA})(\mathrm{nmol} / \mathrm{ml})(\mathrm{Mean} \pm \mathrm{SD})$ \\
\hline K1 & 5 & $3.380 \pm 0.63513$ \\
K2 & 5 & $5.857 \pm 1.48249$ \\
P1 & 5 & $5.352 \pm 0.90144$ \\
P2 & 5 & $4.252 \pm 1.18451$ \\
P3 & 5 & $3.999 \pm 0.98823$ \\
\hline
\end{tabular}

Information:

$\mathrm{K} 1$ : group no treatment

$\mathrm{K} 2$ : groups with exposure to stress

P1 : group with exposure to stress + tea and blood sampling at the first hour,

P2 : group with exposure to stress + tea and blood sampling is taken at $6^{\text {th }}$ hours, and the group

P3 : group with exposure to stress + tea and blood sampling is taken at $24^{\text {th }}$ hours, 
Based on the table, MDA level in the Normal Control Group (K1) was $3.380 \pm 0.63513 \mathrm{nmol} / \mathrm{ml}$. The highest MDA level was in the Stress Control Group (K2) with $5.857 \pm 1.48249 \mathrm{nmol} / \mathrm{ml}$. MDA level of the P1 Experimental Group was $5.352 \pm 0.90144 \mathrm{nmol} / \mathrm{ml}$, the P2 Experimental Group was $4.252 \pm 1.18451 \mathrm{nmol} / \mathrm{ml}$ and MDA level in the P3 Experimental Group was $3.999 \pm 0.98823 \mathrm{nmol} / \mathrm{ml}$.

MDA levels in all groups had a normal distribution ( $p>0.05)$ using Kolmogorov-Smirnov test. Normal Control Group (K1) with $\mathrm{p}=0.902$, Stress Control Group (K2) with $\mathrm{p}$ value $=0.989$, P1 Experimental Group with p-value $=0.955, \mathrm{P} 2$ Experimental Group with $\mathrm{p}$ value $=0.380$, and P3 Experimental Group with p-value = 0.945 . Homogenity test by using Lavene Test on MDA data showed homogeneous data on all groups of experimental animals with $\mathrm{p}=0.401(\mathrm{p}>0.05)$. Manova test in all experimental groups on MDA levels showed $\mathrm{p}=0.01<0.05$. So, it could be stated that there was significant difference of MDA level to giving robusta coffee in all group of experiment animals.

The result of LSD test at MDA level is shown in Table 2.

Table 2. The p-value of $L S D$ test of malondialdehyde (MDA) levels

\begin{tabular}{cccccc}
\hline Group & K1 & K2 & P1 & P2 & P3 \\
\hline K1 & & 0.002 & 0.009 & 0.215 & 0.374 \\
\hline K2 & 0.002 & & 0.467 & 0.029 & 0.013 \\
\hline P1 & 0.009 & 0.467 & & 0.122 & 0.061 \\
\hline P2 & 0.215 & 0.029 & 0.122 & & 0.715 \\
\hline P3 & 0.374 & 0.013 & 0.061 & 0.715 & \\
\hline
\end{tabular}

Information:

$\mathrm{K} 1$ : group no treatment

$\mathrm{K} 2$ : groups with exposure to stress

P1 : group with exposure to stress + tea and blood sampling at the first hour,

P2 : group with exposure to stress + tea and blood sampling is taken at $6^{\text {th }}$ hours, and the group

P3 : group with exposure to stress + tea and blood sampling is taken at $24^{\text {th }}$ hours

Based on Table 2, there was a significant difference in Control Group K1 with K2 ( $\mathrm{p}=0.002)$. Similarly, there were significant differences of Control Group K2 to Treatment Group P2 ( $p=0.029)$ and P3 $(p=0.013)$. But there was no significant difference between P1, P2 and P3.

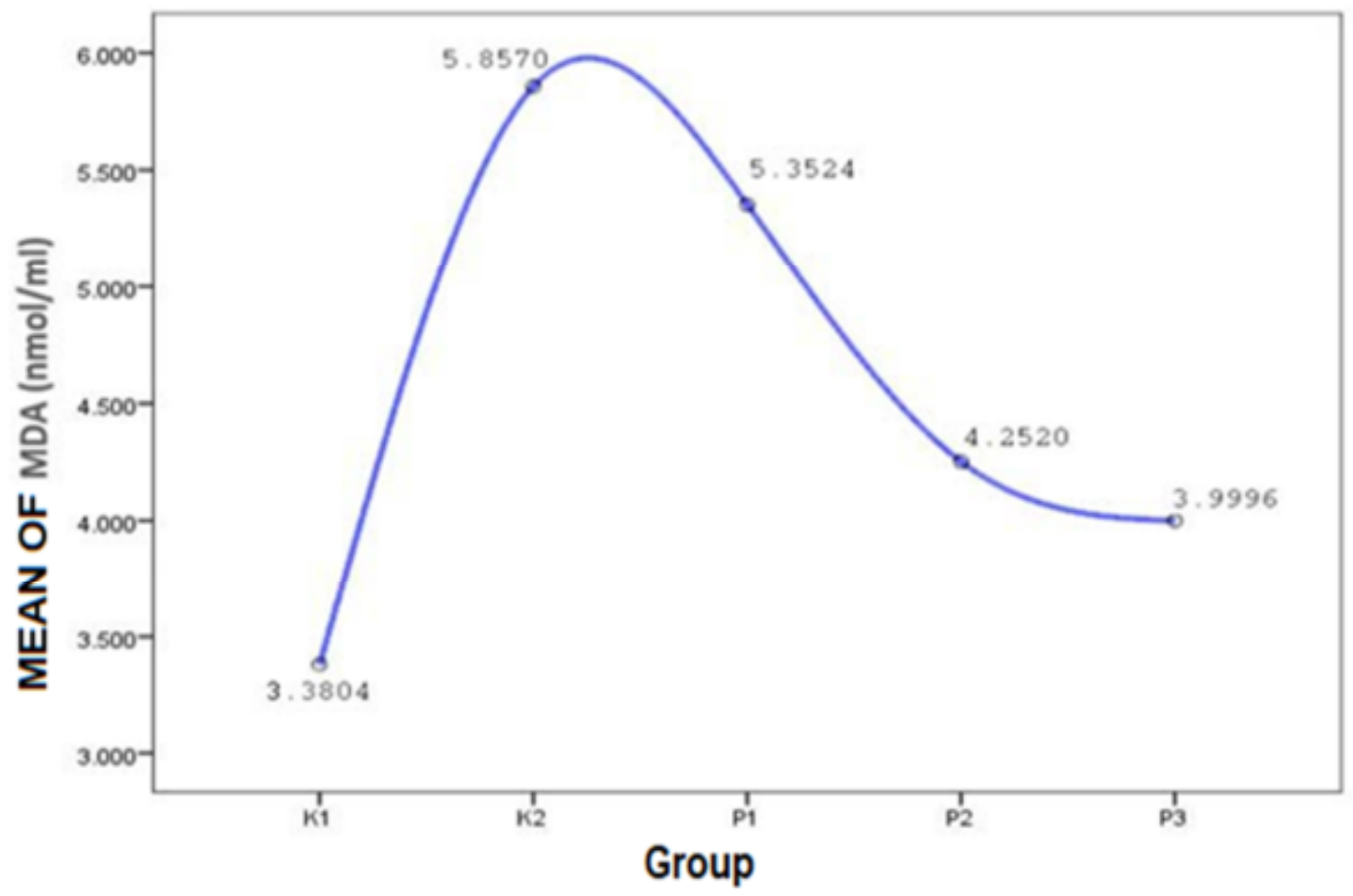

Figure 1. The mean of malondialdehyde (MDA) levels in experimental group 
Based on Figure 1, it was known that the Normal Control Group (K1) and experimental group (P1, P2, and P3) were different from the Stress Control Group (K2). There was a noticeable difference in the Stress Control Group (K2), where the mean MDA levels was higher than the Normal Control Group (K1) and the highest of all groups.

\section{DISCUSSION}

The treatment given to stress that occurs on night sleep guard. Exposure to disturbances in sleep patterns leads to stress from experimental animals resulting in an increase in the hormone Corticotropic Releasing Hormone $(\mathrm{CRH})$ that can secrete high cortisol which is an activity of Hypothalamic-Pituitary-Adrenal axis $(\mathrm{HPA})^{(9)}$. Due to the emphasis on the HPA axis will cause and increase the activity of the sympathetic nervous system and adrenal response. Increased sympathetic system resulted in the release of local norephinephrine neurotransmitters on sympathetic nerve endings. While the activity of the stressor on the adrenal medulla is to release epinephrine, so this epinephrine causes vasoconstriction in the blood vessels ${ }^{(10)}$. At elevated blood pressure, the fluid can squeeze the blood vessels next to it, perpendicular to the direction of blood flow ${ }^{(11)}$. In this situation, there is an emphasis on blood vessel walls and the flow of blood that is perpendicular to each other or bias is called the circumference voltage, causing turbulence that causes no oxygen distribution into the network properly. The occurrence of this maldistribution leads to tissue hypoxia which affects the decrease in oxygen saturation. From the stretching of blood pressure, the pressure / circular stress on the walls of these blood vessels, also results in increased superoxide production in the endothelium and smooth muscle cells, in which the superokside is a free radical ${ }^{(12)}$. Increased superoccuples production can not be separated from the role of regulated NADPH oxidase, mitochondrial oxidase and xanthine oxidase.

The formation of free radicals in the form of superoxide anions $\left(\mathrm{O}_{2}^{-}\right)$described above triggers a series of enzymatic reactions. Among other free radical reactions with fatty acids that produce lipid peroxide ${ }^{(13)}$. These lipid peroxidation events in erythrocytes cause lysis or known as hemolysis. This reaction causes the release of Malondialdehide (MDA) which furthermore this compound will cause cell damage ${ }^{(14)}$.

The decrease in MDA levels in the group given the Green Tea (EGCG) proved to have antioxidant effects. Green tea leaves contain flavonoid groups of polyphenols that act as dampers that can neutralize free radicals as xantin oxidase inhibitors and prevent lipid peroxidase reactions by scavenging $\mathrm{O}_{2}^{-}$resulting from NADPH reactions that are the beginning of $\mathrm{ROS}^{(15)}$. Significant changes between groups of K2 to P1, P2 and P3 only significant changes at the 6th (P2) and 24th (P3) hours, as EGCG reached its maximum plasma concentration at 1.3 to 2.2 hours after consumption oral ${ }^{(16)}$. This proves that at $1^{\text {st }}$ hour $(\mathrm{P} 1)$ has not undergone significant changes, even though it has been an average decrease in the value of Malondialdehide.

\section{CONCLUSION}

Green tea with its active ingredients Epigalocatechin (EGCG) has an important role as an antioxidant. And this has been demonstrated both epidemiologically and pharmacologically ${ }^{(17)}$. Green tea polyphenols with the ability of scavenge reactive oxygen species (ROS) by producing more stable phenolic radicals. The experiment using this spectromagnetic resonance (EPR) electron electron also shows that EGCG can scavenge $\mathrm{OH}$ and $\mathrm{O}_{2}^{-}$which is the result of the NADPH reaction, which is the beginning of the $\operatorname{ROS}^{(15)}$.

\section{REFERENCES}

1. Lei Wang, Gong Muxin, Hiroshi Nishida, Chieko Shirakawa, Shinji Sato, and Tetsuya Konishi. 2006, Psychological Stress-Induced Oxidative Stress as a Model of Sub-Healthy Condition and the Effect of TCM, Evid Based Complement Alternat Med. 2007;4(2):195-202.

2. Woolston C. Work \& Health: Job Stress [Internet]. 2009. Available from: http://www.cvshealthresources.com/topic/safework.

3. Trilling JS, Jaber R. Selections from current literature: the role of free radicals and antioxidants in disease. Fam Pract. 1996;13(3):322-6.

4. Kothari S, Thompson A, Agarwal A, Plessis S. Free Radical: Their Beneficial and Detrimental Effects on Sperm Function. Indian Journal of Experimental Biology. 2010;48:425-435.

5. Marciniak A, Brzeszczyńska J, Gwoździński K, Jegier A. Antioxidant Capacity and Physical Exercise. Biology of Sport. 2009;26(3):197-213.

6. Tanaka T, Kusano R, Kouno I. Synthesis and antioxidant activity of novel amphipathic derivatives of tea polyphenot \& oorganic. Medical Chem. 1998;8:1801-1806.

7. Chung HY, Yokozawa T, Dong E, Oura H, Nakayawa H. Inhibitory effect of green tea on injury to cultured neral epithelial cell line. LLC-PK, Biosci, Biotechnol, Biochem. 1997;61:204-206. 
8. Grotto D, Maria LS, Valentini J, Paniz C, Garcia GS, Pomblum VJ. et al. Importance of the lipid peroxidation biomarkers and methodological aspects for malondialdehyde quantification. Quimm Nova 2009;32(1):169-74.

9. Jauch CK, Schmid SM, Hallschmid M, Kerstin. Pituitary-Gonadal and Pituitary-Thyroid Axis Hormone Concentrations before and during a Hypoglycemic Clamp after Sleep Deprivation in Healthy Men, PLoS ONE. 2013;8(1):e54209.

10. Norman AW, Litwack G, Hormone academic press, Inc, San Diego New York. Boston. 1987:450-69.

11. Zhang W, Liu Y, Kassab GS. Flow-induced shear strain in intima of porcine coronary arteries. J. Appl. Physiol. 2007;103:587-593.

12. Inoue N, Kawashima S, Hirata KI, Rikitake Y, Takeshita S, Yamochi W, Akita H, Yokoyama M. Stretch force on vascular smooth muscle cells enhances oxidation of LDL via superoxide production. Am. J. Physiol. Heart Circ. Physiol. 1998;274:H1928-H1932.

13. Jones W. Noni blessing holdings. Food Quality Analysis. Oregon; 2000.

14. Droge W. Free Radicals in the Physiology Control of Cell Function. Physiol Rev. 2003;82:47-95.

15. Shi XL, Ye JP, Leonard SS, Ding M, Vallyathan V, Castranova V, Rojanasakul Y, Dong ZG. Antioxidant properties of (-)-epicatechin-3-gallate and its inhibition of $\mathrm{Cr}(\mathrm{VI})$-induced DNA damage and $\mathrm{Cr}(\mathrm{IV})-\mathrm{or}$ TPA-stimulated NF-kappa B activation. Mol Cell Biochem. 2000;206:125-132.

16. Naumovski N, Blades BL, Roach PD. Food Inhibits the Oral Bioavailability of the Major Green Tea Antioxidant Epigallocatechin Gallate in Humans. Antioxidants. 2015;4:373-393.

17. Tanaka T, Kusano R, Kouno I. Synthesis and antioxidant activity of novel amphipathic derivatives of tea polyphenot \& oorganic. Medical Chem. 1998;8:1801-1806. 